\title{
Aspectos Institucionais da Unificação das Polícias no Brasil*
}

Mateus Afonso Medeiros

\section{INTRODUÇÃO}

Tte trabalho aborda a unificação das polícias estaduais brasilei-

¿ ras, militares e civis. Meu enfoque não está na conveniência da unificação para o controle da criminalidade. A literatura sobre as polícias é controversa quando se trata de afirmar uma relação entre crime e prática policial (Bayley, 1994). As organizações policiais atuam em ambientes altamente institucionalizados, nos quais, mais que a eficiência, conta o fator legitimidade. Minha pergunta não é se a eventual unificação reduzirá os índices de criminalidade, mas se aumentará a legitimidade das polícias aos olhos de quem deve legitimá-las.

A existência de, no mínimo, duas polícias atuando no mesmo espaço geográfico (o âmbito das províncias e, mais tarde, dos estados federados) tem sido o nosso padrão histórico desde o Império (1822-1889) ${ }^{1}$. Partindo dessa constatação, por que as recentes e reiteradas tentativas, por parte de políticos e da sociedade civil, de unificar as atuais Polícias Militares e Civis ${ }^{2}$ A resposta está relacionada à extensão da cidadania no Brasil (Carvalho, 2002), que acarretou (a) a ampliação

\footnotetext{
* O autor agradece imensamente aos professores Arthur Costa, Rebecca Abers, Marco Cepik e Leonardo Barbosa, bem como aos pareceristas de Dados, pelos comentários a versões anteriores deste artigo.
}

DADOS - Revista de Ciências Sociais, Rio de Janeiro, Vol. 47, n-2, 2004, pp. 271 a 296. 
qualitativa e quantitativa das fontes de legitimidade das polícias e (b) a transformação de seu papel no controle social. De um lado, a progressiva suplantação das estruturas clientelistas e a construção da democracia tornam as polícias responsabilizáveis perante um universo político mais extenso; de outro, as polícias abandonam antigas funções de controle social e concentram-se no controle da criminalidade comum, atividade para a qual a estrutura de duas polícias é vista como inadequada (Dallari, 1993; Silva Filho, 2001; Bicudo, 2000).

Entretanto, como a idéia de unificação funciona como mito institucional (vide próxima seção), terá de competir com outros mitos do ambiente institucional (Meyer e Rowan, 1991). De maneira alguma há consenso sobre a unificação entre os atores envolvidos na construção da legitimidade das polícias. Meu objetivo é apontar aspectos pertinentes a essa disputa. Para tanto, utilizarei a idéia de campo institucional (Lin, 2001). A principal conclusão será a de que, no Brasil, não se completou a institucionalização de um campo policial. As polícias responderam a demandas vindas de outros campos, notadamente o da Justiça (Polícia Civil) e o da Defesa (Polícia Militar). Dessa perspectiva, a proposta de unificação pode ser encarada como uma tentativa de transformar a natureza das demandas sobre as organizações policiais.

As referências empíricas deste artigo foram buscadas na literatura em geral sobre as polícias brasileiras, especialmente sobre as organizações de São Paulo, Minas Gerais e Rio de Janeiro. As experiências regionais são diversas, o que gera elementos de identidade e tradição bastante distintos. Minhas conclusões, portanto, têm validade restrita ao âmbito das corporações policiais desses estados. Por outro lado, as organizações policiais brasileiras sempre tiveram características comuns, em termos de regulação legal e de seus papéis no controle social. Não pretendo detalhar diferenças e semelhanças, mas propor uma abordagem da questão que ultrapasse o debate sobre a eficiência no controle do crime.

\section{A POLÍCIA COMO ORGANIZAÇÃO INSTITUCIONALIZADA}

A teoria das organizações tem distinguido entre ambientes técnicos nos quais as organizações são recompensadas pela sua eficiência na realização de uma atividade - e ambientes institucionais - em que a premiação se dá pela adequação de suas práticas a regras e crenças vistas 
como apropriadas e legítimas (March e Olsen, 1984:21-26; Scott e Meyer, 1991) $)^{3}$. Uma organização pode operar em um ambiente mais ou menos técnico, mais ou menos institucional. Há organizações altamente institucionalizadas - como escolas, escritórios de advocacia, igrejas - que têm maior preocupação com sua legitimidade que propriamente com a eficiência ${ }^{4}$. As polícias integram este grupo (Cranke Langworthy, 1992), uma vez que operam em ambientes que exercem grande pressão institucional e menor pressão técnica. Nas palavras de Meyer e Rowan, essas organizações

"[...] são impelidas a incorporar as práticas e procedimentos definidos por conceitos - racionalizados, prevalecentes e institucionalizados na sociedade - do que deve ser o trabalho organizacional. As organizações que agem assim aumentam suas perspectivas de sobrevivência, independentemente da eficácia imediata das práticas e procedimentos adquiridos. Produtos, serviços, técnicas, políticas e programas institucionalizados funcionam como poderosos mitos, e muitas organizações os adotam cerimonialmente. [...] Para manter a conformidade cerimonial, as organizações que refletem regras institucionais tendem a isolar [buffer] suas estruturas formais das incertezas das atividades técnicas" (1991:41) ${ }^{5}$.

O principal instrumento de proteção das organizações altamente institucionalizadas são os mitos institucionais. Os mitos são entendimentos sociais da realidade: prescrições racionalizadas e impessoais cuja aceitação está além da discricionariedade de atores individuais que emprestam natureza técnica a objetivos sociais, especificando de forma normativa os meios para atingir propósitos técnicos.

Três processos explicam o surgimento dos mitos (idem:47-49). Primeiro, a elaboração de redes de relações entre as variadas organizações do ambiente institucional. As transações e trocas entre elas definem estruturas, procedimentos e políticas. Na medida em que essas conexões perduram, as estruturas podem atingir status mítico (Crank e Langworthy, 1992:350). Por exemplo, universidades criam títulos cujo valor institucional é reconhecido pelo mercado de trabalho. Um exemplo para o caso das polícias é o atendimento a chamadas telefônicas. Mesmo que os estudos demonstrem que essa técnica tem pouco impacto sobre as taxas de criminalidade (Bayley, 1994:3), pessoas e organizações associam o pronto atendimento à eficiência policial. 
Um segundo processo consiste na regulação legal do ambiente institucional. A criação de mandatos legais, a regulação de práticas por intermédio de leis ou regulamentos administrativos, o estabelecimento de requisitos para a prática de profissões (Meyer e Rowan, 1991:48). Quanto maior a ordem legal-racional, maior a extensão em que regras e procedimentos racionalizados se transformam em exigências institucionais. No caso dos policiais, cuja profissão é intensamente regulada, surgem mitos relacionados à formação profissional, tais como a noção de que a aplicação da lei penal é uma resposta adequada a problemas de ordem pública (Silva, 2001:73).

Finalmente, o terceiro processo é a própria reação das organizações, por meio de suas lideranças, ao ambiente institucional. As organizações não são passivas; ao contrário, lideranças, associações profissionais estão ativamente engajadas na construção e elaboração dos mitos institucionais. Aqui podemos citar a intervenção de lideranças policiais para justificar socialmente a violência como instrumento de combate ao crime (Paixão, 1985).

\section{A IDÉIA DE CAMPO INSTITUCIONAL}

O que chamamos de ambiente institucional pode ser concebido em termos de uma relação entre organizações, mitos e atores relevantes denominada campo institucional (Lin, 2001; Powell e Dimaggio, 1991). O campo institucional é definido por um processo de isomorfismo entre determinadas organizações, que compartilham mitos e fontes de legitimidade, e que tenderão a adotar as mesmas "regras do jogo" devido à intensa troca de recursos (técnicos e institucionais) que estabelecem entre $\mathrm{si}^{6}$.

Importante para o processo de troca entre organizações é o que Lin (2001:191) denomina organizações institucionalizantes, que são credenciadas, dentro de um campo, a socializar seus membros. Exemplo típico são as universidades, as quais, além de ensinarem a capacidade técnica a seus estudantes, proporcionam a socialização necessária ao aprendizado dos parâmetros institucionais. As redes sociais - compostas de pessoas e grupos que compartilham valores e normas também são um importante fator de geração e troca de recursos. Atores que estão fora do campo, ou que se encontram em posição periférica, podem unir esforços para adentrá-lo, incorporando mitos alternativos e/ou criando novas organizações institucionalizantes. 
Powell e Dimaggio (1991) identificaram três mecanismos de isomorfismo, aos quais chamaram forças isomórficas ${ }^{7}$ : a força mimética, que consiste na imitação organizacional, ou seja, na adoção - intencional ou não - de uma organização preexistente como modelo para a criação de uma nova; a força coercitiva, que é o exercício direto - formal ou informal - de controle de uma organização sobre outra; e a força normativa, que é aquela do padrão profissional - membros de diferentes organizações, oriundos da mesma "profissão", tendem a reivindicar os mesmos direitos e rotinas.

Pode-se falar na institucionalização de um campo quando determinados atores, pertencentes a determinadas organizações e relacionados às mesmas organizações institucionalizantes, adotam soluções organizacionais consideradas legítimas e apropriadas. As organizações passam a sofrer pressões normativas, coercitivas e miméticas, no sentido de se parecerem umas com as outras.

Certamente, a institucionalização é um processo histórico. Existem importantes variações na forma de legitimidade assumida por cada organização. Organizações diferentes nunca terão o mesmo fluxo de recursos. O fato de sofrerem pressões de um campo não as condena a respostas isomórficas (Powell, 1991). Apesar dessa complexidade, os processos de isomorfismo são empiricamente verificáveis. A própria existência dos diferentes "setores" atesta que determinadas organizações possuem a consciência de estarem envolvidas em um empreendimento comum (Powell e Dimaggio, 1991:65). Ambientes complexos criam heterogeneidades e permitem às organizações responderem às demandas estrategicamente.

“Constrangimentos abrem algumas possibilidades ao mesmo tempo que restringem ou negam outras [...]. A institucionalização é sempre uma questão de grau, em parte porque é um processo histórico. [...] Se reconhecermos que os ambientes institucionais são complexos e pudermos identificar as fontes de demandas conflitantes, então poderemos explicar as circunstâncias em que a institucionalização é contestada ou incompleta" (Powell, 1991:195).

Argumento neste artigo que, no Brasil, a institucionalização do campo policial não se completou. Em termos de mitos, atores relevantes e organizações institucionalizantes, as polícias tiveram de responder a demandas vindas de outros campos, notadamente o da Justiça e o da Defesa, localizadas na periferia destes, e não no centro de um campo 
institucional policial. A proposta de unificação pode ser encarada como uma tentativa de transformar a natureza das demandas institucionais sobre as polícias, vale dizer, de alterar seus mitos, atores relevantes e organizações institucionalizantes, na formação de um campo propriamente policial.

\section{O CAMPO INSTITUCIONAL POLICIAL}

O estudo comparado da organização policial revela que as polícias modernas realizam três atividades básicas (Bayley, 1975): (a) a investigação criminal; (b) o uso da força paramilitar, nos casos considerados necessários (distúrbios civis, repressão a movimentos sociais etc.) contra membros da própria comunidade política; e (c) o patrulhamento uniformizado dos espaços públicos, com a prerrogativa de uso da força.

Um possível campo institucional policial contém as organizações que desempenham ao menos uma dessas tarefas. Monjardet (2003) relacionou essas três maneiras de utilizar a força a três tipos ideais de Polícia: a polícia de ordem, a polícia criminal e a polícia urbana. A instituição policial é uma combinação dessas três funções: "O cliente da polícia de ordem é o Estado, o da polícia criminal é o criminoso incontestável, e o da polícia urbana é o cidadão comum, o homem sem qualidades" (idem:284). A rigor, apenas a terceira atividade é marcadamente "moderna"; as outras duas, em épocas passadas, foram realizadas por organizações que se misturavam à justiça criminal e aos exércitos. Sua substituição pelas polícias, nos Estados europeus ocidentais, ocupou um período de duzentos anos, entre os séculos XVII e XIX (Bayley, 1975). Conquanto essas transformações tenham diversos motivos econômicos, sociais e políticos, cabe chamar a atenção para dois mitos institucionais surgidos nesse período, relacionados à evolução do Estado de direito: (1) a noção de que o "exército" a aplicar a força contra os próprios cidadãos de um Estado deve ser diferente daquele a ser empenhado contra não-cidadãos; e (2) a idéia de que a Justiça deve ser imparcial e não deve investigar os crimes que vai punir.

Muitos autores têm relacionado o surgimento das polícias modernas à sua utilização no controle de atividades de massa e das "classes perigosas" (Santos, 1997; Silver, 1967). Os exércitos haviam funcionado como mecanismos de emergência, alternando entre a não-intervenção e os mais drásticos procedimentos (Silver, 1967:12). 
Uma organização policial uniformizada, por sua vez, teria a capacidade de penetrar na sociedade, garantindo a presença permanente da autoridade estatal. Modelando-se nas Forças Armadas, a nova organização aproveitaria as soluções militarizadas na repressão a distúrbios coletivos. Ao mesmo tempo, seu caráter permanente possibilitava uma nova estratégia: o patrulhamento em pequenos grupos, a fim de prevenir a violência e identificar supostos criminosos.

Mas para que essas novas táticas tivessem sucesso, a polícia não poderia se fiar apenas em sua capacidade de coerção. Sem algum assentimento de seu público, que implicasse o desarmamento consentido deste, os custos da nova organização em muito ultrapassariam sua efetividade. A nova agência teria de buscar o reconhecimento como mecanismo legítimo de controle social. A construção de consenso interno e o desenvolvimento da polícia como instrumento de coerção são processos que caminham lado a lado. As Forças Armadas, ao contrário, não precisam da aceitação de seus destinatários (o inimigo). Ambas estão permanentemente organizadas para usar a força. A polícia, entretanto, tem que usar a força limitada, necessária, ou até agir sem usá-la, mesmo que isto signifique gastar mais tempo e recursos. Obviamente, a polícia pode ser empregada como exército, e o exército como polícia, como no caso das forças de paz das Nações Unidas. Mas por ser ideal é que a definição nos interessa: o controle da força, em uma democracia, serve como mito diferenciador entre Polícia e Forças Armadas (Costa e Medeiros, 2003).

Com relação à investigação criminal, a formação das polícias modernas coincide com o fortalecimento das liberdades individuais: o direito à ampla defesa, ao processo contraditório, entre outras, que passam a transformar a maneira como a Justiça está autorizada a atuar na punição de criminosos. Aqui, cabe ressaltar o caráter discricionário e circunstancial do uso da força pela polícia (Bittner, 2003). No "governo das leis", e não "dos homens", a discricionariedade policial realiza a mediação entre um mundo do dever ser (da lei) e um mundo do ser (dos homens).

A Justiça, quando toma conhecimento da prática de um crime, pode condenar ou absolver o réu, mas não pode deixar de processá-lo. Como seria impossível abrir um processo para cada crime que acontece de fato, a Justiça age apenas mediante provocação, delegando a tarefa de escolher quem será processado a outras agências, principal- 
mente à polícia. Na prática, é a polícia quem decide colocar o processo penal em funcionamento. A discricionariedade policial serve para isolar a Justiça da investigação criminal, para que os tribunais possam ser "imparciais". Se o Estado de direito estiver consolidado, espera-se que os abusos cometidos pela Polícia sejam corrigidos pela própria Justiça.

Em resumo, o campo institucional policial é formado pelas organizações que exercem a "polícia de ordem", a "polícia criminal" e a "polícia urbana". As duas primeiras foram anteriormente exercidas por organizações que se misturavam à Justiça e aos exércitos. A última é marcadamente moderna e depende da inserção consensual das polícias no controle social. O desenvolvimento da democracia e a combinação dessas três funções nas mesmas organizações policiais provocaram a necessidade de consenso também com relação às polícias "de ordem" e "criminal".

Cabe atentar para o número de organizações em um dado campo policial. Na Alemanha, até 1975, cada unidade federada organizava sua(s) polícia(s), além de existirem organizações federais (Bayley, 1975:333-340). Na França e Itália, são duas as organizações nacionais, além de forças paramilitares especiais e forças das comunas ou cidades. Na Inglaterra, o número de polícias caiu de 125, em 1960, para 43, em 1974, mantendo-se esta quantidade até 1988 (McKenzie e Gallagher, 1989:7-8). Nos Estados Unidos, em 1980, havia 19.691 forças registradas no Departamento de Justiça (idem).

No Brasil, há duas polícias por estado, três polícias da União, mais uma série de Guardas Municipais. Portanto, não somos exceção em termos numéricos. Entretanto, há uma peculiaridade. Conquanto nos países citados haja unidades paramilitares especiais, em regra cada organização realiza as três tarefas policiais. Sua diferenciação ocorre pelo critério geográfico e não funcional. A especialização se dá no interior das organizações, vale dizer, de maneira intra-organizacional por exemplo, nos Estados Unidos há officers patrulhando as ruas e detectives investigando crimes, mas ambos pertencem à mesma organização. No Brasil, a especialização é extra-organizacional: no mesmo espaço geográfico, uma polícia se ocupa da investigação e a outra executa as tarefas paramilitar e de patrulhamento. 
A especialização extra-organizacional gera conseqüências para o campo institucional. Dificulta a troca de pessoal entre as organizações, visto que os policiais têm "profissões" diferentes (força normativa). A estrutura militar não é vista como adequada às tarefas civis, $\mathrm{e}$ vice-versa (força mimética) ${ }^{8}$. Além disso, durante a maior parte de sua história, as polícias foram completamente separadas em termos de comando (força coercitiva). Apesar do contato diário entre as duas organizações policiais, há pouca troca de recursos técnicos e institucionais. As relações isomórficas são mais fortes entre as diversas Polícias Civis, entre as diversas Polícias Militares e-o mais grave em termos do campo policial - entre Polícia Civil e Justiça, e entre Polícia Militar e Exército. Está incompleta a conquista democrática da separação institucional Polícia-Justiça e Polícia-Exército.

Na seção seguinte, traçarei uma análise histórica das organizações policiais brasileiras, procurando identificar as forças isomórficas que atuaram em sua estruturação.

\section{SENTIDO DA DUPLA ESTRUTURA POLICIAL BRASILEIRA}

Os primeiros vinte anos do Império são marcados pela constante disputa por autoridade política entre uma elite política nacional e elites locais (Carvalho, 1981; Cintra, 1974:62). O equilíbrio se deu no plano das províncias: ali seriam organizadas as eleições, a tributação e as principais forças policiais e competências judiciais (Ferreira, 1999:30). As decisões ficariam a cargo dos presidentes de província (poder central), com influência dos proprietários rurais (poderes locais), mas desde que organizados no plano provincial, o que foi possível por meio da formação das clientelas (Graham, 1997).

$\mathrm{Na}$ estrutura clientelista, faz todo sentido a transferência de poderes oficiais a chefes políticos privados. O controle das Polícias Civis pelos "coronéis" locais serviria para a formação das clientelas. Entretanto, devido à situação de disputa entre centro e periferia, a capacidade de usar de força não poderia implicar a de insubordinação política. A força policial paramilitar subordinar-se-ia estritamente ao presidente de província, colocando-se sob os auspícios do poder central. Ao mesmo tempo, como se destinava ao combate militar propriamente dito (a repressão a rebeliões políticas), e não apenas ao controle de distúrbios civis, a polícia deveria parecer um exército9. 
Tanto a Guarda Nacional quanto as organizações que originaram as Polícias Militares - em São Paulo, o Corpo de Guarda Municipal, mais tarde Corpo Policial Permanente (Fernandes, 1974:21) - serviram ao propósito do poder central de combater rebeliões locais, sendo o papel da Guarda minimizado a partir de 1850 (Castro, 1977). Note-se que não houve preocupação com o controle da força como mito institucional, visto serem aqueles homens preparados para o verdadeiro combate militar. Ocorreu uma "imitação" do Exército (força mimética), vale dizer, a polícia adotou soluções organizacionais militares. Muitos comandantes das Polícias Militares eram recrutados entre os oficiais do Exército ${ }^{10}$.

A Justiça na Colônia havia sido responsabilidade primordial das Câmaras Municipais, eleitas pelos proprietários locais (Prado Junior, 2000). Após uma breve interrupção entre 1822 e 1831, os proprietários locais continuaram a eleger os juízes de paz, que tinham atribuições policiais (investigar, prender) e judiciais (formar culpa, escolher jurados). A partir de 1841, entretanto, uma reforma processual penal transfere grande parte dessas atribuições à nova figura dos delegados de Polícia. Ao contrário do juiz de paz, o delegado não era eleito por chefes locais, mas nomeado pelo poder central. Tal medida não visava, necessariamente, evitar que os senhores locais exercessem um controle social privado. Obrigava-os, entretanto, a compactuar com o poder central.

Apesar de se subordinarem a um membro do Poder Judiciário (o "chefe de Polícia"), não havia requisitos formais para a ocupação do cargo de delegado, cujos ocupantes poderiam ser recrutados entre homens abastados das localidades (Fernandes, 1974:67; Graham, 1997:87). A mistura de poderes judiciais e policiais era fundamental porque permitia a formação das clientelas ${ }^{11}$. Aqui, além da força mimética, percebe-se uma pressão coercitiva exercida pelo Poder Judiciário: a atividade policial era regulada pelo processo penal. Obviamente, a investigação criminal não surge como resultado do mito da imparcialidade da Justiça.

O patrulhamento uniformizado foi a atividade policial que mais tempo demorou a institucionalizar-se no Brasil. Isto porque a base do controle social esteve a cargo das clientelas privadas. Patrulhas uniformizadas existiram nos reduzidos ambientes urbanos. No ambiente rural, conquanto fossem permitidas, serviam menos para o policia- 
mento e mais para a fixação da força de trabalho ociosa (Fernandes, 1974:97).

O patrulhamento cresceu no mesmo passo lento e, posteriormente, no mesmo passo largo da urbanização ${ }^{12}$. Seu controle oscilou entre as organizações militares e as civis, em uma disputa acirrada que reflete a dificuldade de institucionalização de um campo policial. Justamente a atividade policial mais singular foi historicamente a mais enfraquecida $^{13}$.

A República aprofundou o processo de identificação das polícias com o campo da Defesa, de um lado, e o campo da Justiça, de outro. Na política dos governadores - marcada pela disputa entre os partidos estaduais pelo domínio do poder central (Cintra, 1974)-, as polícias atuavam como verdadeiros exércitos. A Força Pública de São Paulo passa a contar com uma artilharia aérea, estando empenhada em conflitos em São Paulo, Paraná, Santa Catarina, Ceará, Bahia, Goiás e Mato Grosso (Moraes, 2001:77). Contrata a Missão Francesa para receber instrução militar em 1905, doze anos antes do próprio Exército Nacional. Em 1932 (Revolução Constitucionalista), entra em guerra contra o próprio Exército. Para vencê-la, Vargas precisou contar com a poderosa polícia de Minas Gerais (Marco Filho, 1999).

Certamente, aí notamos a força isomórfica mimética, ou seja, a imitação da estrutura do Exército. Com o processo de profissionalização definição de carreiras, instrução pela Missão Francesa etc. - vemos a força isomórfica normativa, consagrada pela expressão "militares dos estados". A partir de 1934, na tentativa de controlar o poderio bélico das forças públicas, a nova Constituição declara-as "forças auxiliares e de reserva do Exército", impondo algum controle coercitivo por parte do próprio Exército Nacional.

A reforma processual penal de 1871 retirou dos delegados as atribuições judiciais, mas manteve a Polícia Civil ligada ao processo penal, por meio do mecanismo do inquérito policial, regulado pelo Código de Processo Penal, que estabelece mecanismos coercitivos do Judiciário em relação às polícias. Também houve um processo de profissionalização: cada vez mais se exige o diploma em direito para ocupação do cargo de delegado (força normativa).

Não é a política dos governadores que explica o aprofundamento das forças isomórficas entre Polícia Civil e Justiça, mas a gradual liberali- 
zação da ordem jurídica, sem alteração significativa da ordem social. A escravidão foi abolida, o sufrágio foi ampliado, os direitos individuais legalmente reconhecidos. Não obstante, a sociedade brasileira continuou extremamente desigual. Assim, o Poder Judiciário (espaço da legalidade) passa a depender de uma agência externa para mediar a aplicação da ordem jurídica igualitária. A Polícia Civil transforma-se em um filtro cuja função é interpretar a situação real (desigual) antes que esta chegue ao Judiciário, ou mesmo impedindo que chegue (Kant de Lima, 1995). Eis a força mimética: o inquérito policial funciona como "pré-processo" penal, em que se forma a culpa sem as garantias da ordem jurídica igualitária (Oliveira, 1985).

O pertencimento das Polícias Militar e Civil aos campos da Defesa e da Justiça não implica sua subordinação aos exércitos e tribunais. Minha assertiva é apenas que - em um ambiente em que as polícias trocam recursos institucionais com outras organizações - as trocas privilegiaram as organizações da Defesa e da Justiça, e não as próprias polícias. As forças coercitivas que existem não são únicas nem irresistíveis.

Apenas em 1934 as Polícias Militares foram declaradas "forças auxiliares" do Exército ${ }^{14}$. Entretanto, isto não as impediu de atuar como se exércitos fossem, mesmo antes de 1934. Se assumirmos, de acordo com Costa e Medeiros (2003), que as polícias podem ser militarizadas em seis dimensões autônomas - organização, treinamento, emprego, controle, inteligência e justiça -, veremos que apenas uma dessas dimensões (controle) envolve subordinação direta às Forças Armadas. As demais dizem respeito a processos em que as polícias são indiretamente influenciadas por organizações militares (como os tribunais militares ou sistemas de inteligência), ou tomam as organizações militares como modelo, adotando códigos disciplinares, estratégias de emprego ou hierarquias militarizadas.

Em todo o mundo, as polícias tornaram-se militarizadas em algum grau. As polícias estadunidenses têm estatuto civil, o que não as impede de adotar a hierarquia militar como modelo (dimensão "organização"), nem de empregar unidades paramilitares (dimensão "emprego" $)^{15}$. A tradição brasileira é de maior militarização em todas as dimensões, mas é falsa a polarização entre aqueles que, por um viés, identificam no vínculo formal Polícia-Exército as marcas da ditadura 
militar (Zaverucha, 1992) e, por outro, reconhecem apenas uma estética militar remanescente nas polícias (Sapori e Souza, 2001).

De um lado, alguma vinculação formal entre Exército e Polícia existe desde 1934, não apenas como resultado de ditaduras militares, mas como uma necessidade do poder central - civil e militar - de controlar corporações que podem atuar, na prática, como exércitos ${ }^{16}$. O governo civil mais estável dos últimos vinte anos - o de Fernando Henrique Cardoso -, em exposição de motivos de sua proposta de reforma das polícias (Proposta de Emenda Constitucional - PEC 514/1997), defendeu um arranjo em que cada estado poderia "estabelecer quais os órgãos de segurança pública a serem criados". Entretanto, a emenda mantém a natureza de "força auxiliar" das polícias, caso os estados optem por corporações militares. Mais ainda, a proposta cria uma nova guarda nacional, composta por membros das polícias estaduais civis e militares ${ }^{17}$.

De outro lado, apesar de sua expressiva desmilitarização nas dimensões do treinamento e do emprego (comparando a situação atual com o passado), as polícias permanecem militarizadas quando se trata de código disciplinar, justiça, poder de veto exercido pelo Exército, e mesmo de seu emprego, como atestam as constantes "invasões" de favelas no Rio de Janeiro, o histórico das Rondas Ostensivas Tobias de Aguiar-ROTA, em São Paulo, ou o recente episódio, em 1999, em que o então governador Itamar Franco (MG) ameaçou usar a Polícia Militar para "defender" Furnas contra a privatização.

Tampouco pretendo afirmar a subordinação das Polícias Civis ao Poder Judiciário. As organizações policiais em todo o mundo integram sistemas de justiça criminal, mais ou menos articulados, que envolvem atores independentes, como juízes, policiais e promotores. As polícias atuam nesses sistemas por meio de padrões de "cooperação antagonística", que revelam instâncias de conflito e rivalidade interorganizacional (Paixão, 1982:64).

Se atuar como agência do sistema criminal é uma função comum a muitas polícias, no caso das Polícias Civis brasileiras, é a própria razão de ser da organização. Ao mesmo tempo, configura uma tarefa proibida às Polícias Militares. Os policiais militares, ao patrulharem as ruas, atuam na definição discricionária de quando se deve ou não 
acionar a lei penal. Mas encerram sua participação ao entregarem supostos criminosos à autoridade policial civil.

Segundo pesquisa realizada pelo Instituto de Estudos Econômicos, Sociais e Políticos de São Paulo - IDESP com delegados de Polícia de nove unidades da federação, a principal característica de um bom delegado é a "capacidade de preparar inquéritos bem circunstanciados", seguida pelo "saber jurídico" (Sadek, 2003:18) ${ }^{18}$. Pesquisa coordenada por Minayo e Souza (2003:163-181) - com policiais civis fluminenses de todos os níveis hierárquicos e funcionais - ressalta a imagem dos policiais como profissionais de investigação. Essa investigação, entretanto, acontece no âmbito do inquérito, cujos procedimentos são regulados pelo mesmo Código de Processo Penal que define o trabalho do juiz e do promotor ${ }^{19}$.

Sem dúvida, não se deve confundir a atividade da polícia judiciária com a rotina prática do distrito policial. O produto final do trabalho policial é a classificação formal de indivíduos em artigos das leis criminais. A investigação, entretanto, busca menos a apuração do crime e mais a identificação, na "clientela marginal" da organização, de possíveis autores dos crimes. Para tanto, a polícia utiliza estoques de conhecimento anteriores ao inquérito, especialmente tipificações organizacionais que articulam ação criminosa e atores típicos (Paixão, 1982:74-75).

Mas a disjunção entre atividades formais e práticas não torna sem importância o fato de que a estrutura das Polícias Civis é análoga à do Poder Judiciário. “É através da crença de que atividades práticas derivam e são controladas pelo desenho racional da estrutura que as organizações adquirem legitimidade junto ao ambiente externo" (idem:66). Dissemos acima que, no ambiente institucional, a regulação de práticas por meio de leis, o estabelecimento de requisitos para a prática de profissões, aumentam a extensão em que procedimentos racionalizados se transformam em requisitos institucionais. Realizar o inquérito, mesmo que de forma diferente daquela prescrita na lei, torna-se a principal função de uma organização que precisa se legitimar, perante os atores relevantes, para garantir sua sobrevivência. Por sua vez, o inquérito não é orientado para a administração de conflitos, mas para a "inexorável punição dos transgressores" (Kant de Lima, 2003:252). Segurança pública e aplicação da lei penal confundem-se. 


\section{A Caminho da Unificação?}

As palavras de Jorge da Silva, acadêmico e coronel da Polícia Militar do Rio de Janeiro, são auto-explicativas na definição dos mitos institucionais das duas corporações policiais:

"Conduzida a atividade policial por operadores do direito, prevalece a visão segundo a qual os problemas do crime e da ordem pública se resolvem com a lei penal. Conduzida a atividade por militares, sobretudo do Exército, os problemas se resolveriam com a força. Na ótica penal, falar de segurança pública consiste normalmente em falar de crime e de criminoso [...]. Esta perspectiva tem dificuldade de enxergar o crime no atacado, como um fenômeno sociopolítico e histórico, e sequer olha para aquelas questões da ordem pública que nada tenham a ver com crime. [...] Se a violência campeia, seria porque faltam leis mais duras; seria porque 'a polícia prende e a justiça solta'; seria por causa da burocracia dos inquéritos; da falta de pessoal e recursos materiais nas delegacias [...]. A avaliação da polícia em geral relaciona-se à quantidade de inquéritos realizados e de infratores levados aos tribunais, pouco importando as ações de prevenção, os crimes que não tenham caído nas malhas do sistema, perdidos na imensidão das 'cifras obscuras'; e os crimes que podem vir a ocorrer.

Na ótica militar, falar de 'ordem pública' é, curiosamente, falar de desordem pública, de combate, de guerra, contra inimigos abstratos que, no atacado, estariam à espreita em lugares suspeitos e determinados [...]. Considerando o crime como uma patologia intolerável e os conflitos de interesses [...] como 'desarrumação' da 'ordem' [...], o modelo militar tem a pretensão de 'vencer' os criminosos [...], de erradicar o crime, de 'acabar' com a 'desordem'. [...] Com preocupação com os criminosos em abstrato, portanto, imagina-se que se a violência campeia é porque os efetivos são insuficientes; porque a polícia judiciária fica nas delegacias [...]; porque a polícia está menos armada que os bandidos; porque faltam motivação e 'garra' aos policiais. Curiosamente, a avaliação do desempenho da polícia é feita como se alguém quisesse demonstrar a sua incompetência. [Q]uanto maior o número (e o tamanho) de 'cercos', 'incursões', 'operações', 'ocupações' e blitze, tanto melhor. Nem pensar em séries históricas das taxas de criminalidade e de vitimização.

[N]a prática, esta visão penalista-militarista da segurança pública consolidou-se entre nós. É com este modelo duplamente enviesado na 
cabeça que os policiais (e o poder político também) operam" (2001:73-75).

Duas características desse texto chamam a atenção: a certeza da ineficiência dos mitos institucionais preponderantes e a impotência do ator individual, membro de uma das organizações, diante da realidade institucional. Não basta a demonstração da ineficiência das práticas, pois os mitos estão institucionalizados na cabeça dos policiais (organização) e do poder político (ator relevante).

Mas, então, de onde viria a idéia de unificação? Afirmei acima que a formação das polícias modernas respondeu a necessidades de controle social. A nova organização era, ao mesmo tempo, repressora - na medida em que exercia o monopólio da violência física legítima - e protetora - uma vez que existia para garantir um consenso social. Santos (1997) chamou essa ambivalência entre o exercício da coação física e a promoção do consenso de "dilema entre a arma e a flor". Na democracia, as três funções policiais experimentam esse dilema.

A história brasileira foi marcada pelo predomínio das Polícias "de ordem" e "de criminalidade", sem que se aplicasse a essas funções os mitos institucionais característicos da democracia e do Estado de direito. A segunda metade do século XX marcou o desenvolvimento de uma polícia "urbana" de patrulhamento, especialmente a partir da década de 60, quando os currículos das polícias uniformizadas passam a incluir menos disciplinas "militares" e mais disciplinas "civis" (Sapori e Souza, 2001). As polícias passam a sofrer pressões no sentido de redesenhar o seu papel. Suas funções eleitorais já estavam mais ou menos enterradas desde a Revolução de 1930. Ao mesmo tempo, se a federação brasileira não atingiu propriamente um equilíbrio, tornou-se suficientemente estável a ponto de dispensar (ou diminuir) os exércitos estaduais. Desa pareceram os movimentos armados característicos da formação política brasileira.

Entretanto, o contexto não democrático tornava difícil traduzir essa expressiva "desmilitarização" em termos da construção de um consenso sobre o papel das polícias, cuja resposta continuava privilegiando a "arma" em vez da "flor". A Constituição "cidadã" de 1988 marca o momento a partir do qual a sociedade brasileira passa a reivindicar também a "flor". A "arma" possui menos destinatários específicos ("clas- 
ses perigosas", grupos políticos). Seu "cliente" é a população como um todo. A polícia é vista como serviço público essencial ${ }^{20}$.

Além dos controles da Justiça (comum e militar) e do Exército, as polícias passam a ser controladas pelo Ministério Público, instituição que representa toda a sociedade na supervisão de serviços públicos. Alguns estados criam outras agências de controle externo, como as ouvidorias de Polícia. No rastro do crescimento da criminalidade, acadêmicos, movimentos sociais, políticos e as próprias lideranças policiais discutem a questão da segurança pública como nunca haviam feito antes (Soares, 2000; Kant de Lima et alii, 2000). A discussão se dá tendo como pano de fundo o paradigma do Estado democrático de direito (Cerqueira, 1996).

A crescente base de legitimidade das polícias exige uma atuação cada vez mais embasada no princípio da igualdade perante a lei. As polícias passam a responder não apenas à burocracia central e a poderes privados locais, mas ao conjunto da comunidade política. Ao mesmo tempo, precisam reagir ao aumento da criminalidade. A grande distância organizacional entre as duas polícias passa a ser vista como fator de ineficiência na realização dessa tarefa (Dallari, 1993; Silva Filho, 2001).

Em termos da idéia de campo institucional, portanto, estamos falando do surgimento de mitos institucionais alternativos e de mudança na natureza dos atores relevantes. Entretanto, mesmo que esses novos atores sejam bem-sucedidos na alteração dos mitos institucionais, isso não garante uma futura unificação.

Primeiro, a unificação é apenas um dos vários caminhos. Beato Filho (s/d), por exemplo, argumenta em favor de soluções "minimalistas" no âmbito do gerenciamento das relações da polícia com o público. Evita, assim, a falsa premissa de que haja uma estrutura ideal de polícia democrática. O público deve perceber a polícia como instituição confiável, capaz de responder aos "problemas de polícia". Dessa perspectiva, o fundamental não é que as polícias sejam unificadas, mas que as organizações aprendam a trocar recursos entre si.

Segundo, organizações altamente institucionalizadas tendem a sair de crises de legitimidade mediante ritos cerimoniais, em vez da efetiva reestruturação organizacional. Crank e Langworthy (1992) descreveram a tendência, nas polícias estadunidenses, de degradação pú- 
blica do chefe de Polícia e sua substituição por outro com "mandato legitimante". No Brasil, podemos traçar um paralelo com a inclinação das polícias para resolver crises por meio de grandes operações de demonstração da eficiência policial, como as recentes operações para prender o traficante Elias Maluco, pela Polícia Civil do Rio de Janeiro.

Terceiro, como já salientei, as experiências regionais são muito diversas. A unificação exige a aprovação de uma emenda constitucional, ou seja, de três quintos dos estados da federação, representados por seus senadores. Cada estado sofre de maneira diferente os fenômenos da criminalidade, da extensão da cidadania, da institucionalização das polícias. A organização das forças policiais no âmbito constitucional - vista como uma padronização excessiva, como uma "indiferença pelas diferenças" - tem sido bastante criticada por estudiosos e reformadores (Coelho, 1989). Mesmo que se alcance um grande consenso em torno da unificação, digamos, em São Paulo, este não será suficiente $^{21}$. Um eventual consenso com relação à unificação terá de ser um consenso federativo ${ }^{22}$.

Se perspectivas de unificação existem, são bastante incertas. Mais útil que fazer exercícios de futurologia será identificar as forças de aproximação das duas polícias. No plano das forças coercitivas, destaca-se a já citada subordinação das polícias à mesma Secretaria de Segurança Pública adotada por vários estados nos últimos anos ${ }^{23}$. Ainda, vários estados criaram conselhos de "defesa social" ou de "segurança pública", com maior ou menor poder deliberativo, nos quais têm assento ambas as polícias. Finalmente, vislumbra-se que o Poder Executivo federal venha a ter maior participação na política de segurança, o que forçaria uma maior padronização, pois o governo tenderia a exigir a mesma contrapartida em troca da liberação de recursos financeiros.

Em termos das forças normativas, destacam-se as recentes reelaborações dos códigos de ética e dos currículos das academias de Polícia Militar nos estados onde a Polícia tem maior tradição profissional, como Rio de Janeiro, Minas Gerais e Rio Grande do Sul. Essa revisão se dá em meio a uma crise de identidade devido à percepção, pelos próprios policiais, da inadequação da instrução militar para o trabalho policial (Muniz, 2001:10-12). 
Em termos de novos atores e redes sociais, pode crescer nos próximos anos a atuação de associações civis cujos membros são policiais "progressistas" de ambas as corporações ${ }^{24}$. Também é fundamental destacar o papel da universidade, com seus recém-criados centros de pesquisa em criminalidade, segurança pública e violência, que oferecem cursos de especialização freqüentados, inclusive, por policiais civis e militares (Kant de Lima, 2003). A universidade funciona como organização institucionalizante alternativa.

Finalmente, o principal indicativo de força mimética são as "operações conjuntas" de ambas as polícias, sendo que algumas dessas experiências utilizam expressamente a idéia de "integração" das polícias (Brasil e Abreu, 2002). Destaca-se a proposta de unificação metodológica em termos de coleta e armazenamento de dados, por intermédio do Sistema Único de Segurança Pública ${ }^{25}$. É de se notar, ainda, o surgimento, no plano internacional, de um "setor" especializado em polícia, com linhas de financiamento, think tanks, tecnologias, conferências etc. Como grande parte das polícias do mundo ocidental é unificada (em termos das atividades do campo policial), pode-se supor que as forças miméticas atuarão sobre as polícias brasileiras no sentido de aproximá-las.

\section{CONCLUSÃO}

Procurei perceber a unificação das polícias de um ponto de vista institucional. Tal perspectiva foi útil porque nos permitiu afastar a armadilha da defesa da unificação como solução eficiente para o problema do crime. Em ambientes altamente institucionalizados, o fator eficiência tem menor importância.

Não obstante, a proposta de unificação é reiterada e, portanto, tem significado para o futuro da organização policial como uma idéia capaz de influenciar as mudanças institucionais (Weir, 1992). A partir das noções de mito institucional, atores relevantes e de campo institucional, foi possível identificar uma tendência à maior institucionalização do campo propriamente policial, em detrimento dos campos judicial e militar. Nesse sentido, a proposta de unificação pode ser vista como democrática, independentemente de critérios técnicos e relaciona-se à noção de que Polícia, Justiça e Forças Armadas são organizações distintas. A tendência de institucionalização do campo 
policial pôde ser identificada. Até onde ela irá, entretanto, é uma questão a se resolver na história e na política.

(Recebido para publicação em janeiro de 2004)

(Versão definitiva em março de 2004)

\section{NOTAS}

1. A divisão remonta à vinda da Corte portuguesa. D. João criou, em 10 de maio de 1808, a Intendência Geral de Polícia da Corte, considerada o embrião da polícia civil fluminense. Um ano mais tarde, estabeleceu-se a Guarda Real de Polícia da Corte, para o patrulhamento da capital (Santos, 1985:17). Como as polícias estão ligadas ao processo de formação do Estado (Bayley, 1975), preferi tomar o Império como referência.

2. A unificação foi proposta, por exemplo, pelo deputado federal Hélio Bicudo (PEC 46/91), pela deputada federal Zulaiê Cobra (PEC 613/98), pela Comissão Mista Especial de Segurança Pública do Congresso Nacional (2002) e pelo Fórum Nacional de Ouvidores de Polícia (2000).

3. “[...] ambientes técnicos são aqueles em que um produto ou serviço é trocado num mercado que remunera as organizações pelo controle eficiente e efetivo de seus sistemas de produção. [...] ambientes institucionais são [...] aqueles caracterizados pela elaboração de regras e requisitos aos quais as organizações individuais devem conformar-se para receber apoio e legitimidade. [...] As organizações são recompensadas por conformar-se a regras e crenças, qualquer que seja a fonte destas" (Scott e Meyer, 1991:123, ênfases no original).

4. Firmas manufatureiras são exemplos de organizações em que predomina o ambiente técnico, enquanto bancos e hospitais sofrem pressões técnicas e institucionais.

5. As traduções das citações em inglês são minhas.

6. "Pode-se dizer que determinadas organizações integram um campo institucional quando respeitam e reconhecem um conjunto específico de instituições. Ao ajustarem suas estruturas internas e padrões de comportamento, as organizações reduzem os custos de transação na interação com outras organizações ditadas pelas mesmas instituições" (Lin, 2001:188).

7. Os autores usam a expressão campo organizacional, em vez de campo institucional. Os dois termos não são contraditórios, mas complementares. Lin (2001) e Powell e Dimaggio (1991) falam de um mesmo processo de isomorfismo, visto por dois diferentes ângulos. Enquanto o isomorfismo institucional enfatiza o viés normativo - a idéia de regras -, o isomorfismo organizacional remete à idéia de atividade ou função. 
8. Muitos policiais civis prestam concurso para as carreiras do Ministério Público e da Justiça, mas raramente se interessam pela carreira policial militar. Nos estados de profissionalização tardia das polícias civis, era comum encontrar policiais militares "fazendo as vezes" de delegados (Brasil e Abreu, 2002:328). Isso sempre foi visto pelos delegados "de carreira" como uma anomalia. Depois da Constituição de 1988, muitos promotores e juízes deixaram de aceitar inquéritos feitos por policiais militares. Por fim, nos estados de profissionalização tardia das polícias militares, até a década de 90, era comum a incorporação automática, sem concurso público ou curso de formação específico, de oficiais do Exército nos quadros das polícias militares.

9. Não poderia ser $o$ Exército devido à grande desconfiança que a elite civil imperial nutria com relação ao militares, tendo submetido o Exército ao que Coelho (1976:34-58) chamou de "política de erradicação".

10. "O tom que dita o processo [de criação da Polícia Militar de São Paulo] é de um militarismo 'civilista', entendido como um militarismo perfeitamente controlado pela 'sociedade civil', ou seja, um militarismo apolítico - no sentido de não ser, ao contrário do que ocorreu com algumas alas do Exército, ameaçador, mas reforçador do status quo" (Fernandes, 1974:71).

11. “[O]s delegados não apenas acusavam, mas também reuniam provas, ouviam testemunhas e apresentavam ao juiz municipal um relatório escrito da investigação, sobre o qual baseava seu veredicto. Além de expedir mandados de prisão e estabelecer fianças, eles mesmos julgavam delitos menores, como a infração de normas municipais." (Graham, 1997:88)

12. O efetivo da Força Pública (Polícia Militar) de São Paulo cresceu de 12.218 homens, em 1951, para 31.000 homens, em 1963, e para 50.000, em 1970 (Moraes, 2001:73-75).

13. A província de São Paulo criou, em 1875, a Guarda de Urbanos, sob o comando da Polícia Civil. De 1891 a 1892 ela passa ao comando da Polícia Militar, como uma especialização intra-organizacional. Depois, entre 1897 e 1901, volta ao controle da Polícia Civil, com o nome de Guardas Cívicos da Capital. Em 1901, é novamente incorporada à Força Pública, como uma especialização intra-organizacional. Em 1926, volta à Polícia Civil, sob o nome de Guarda Civil. Finalmente, em 1969, é fundida com a Força Pública na criação da Polícia Militar do Estado de São Paulo (Fernandes, 1974).

14. A Constituição de 1946 manteve a vinculação das polícias ao Exército. Entretanto, os estados ficavam livres para criar outras corporações de policiamento ostensivo, como as Guardas Civis, além de contarem com ampla discricionariedade no tocante à organização, formas de emprego das polícias e garantias de seus membros. $\mathrm{O}$ Decreto-Lei nº 317 / 67 inaugurou um controle mais rígido por parte do Exército. A Inspetoria Geral das Polícias Militares, órgão do Exército criado em 1969, controlava os currículos, a distribuição geográfica dos batalhões e até as listas de promoção das polícias. O controle pelas Forças Armadas passa a ser cada vez mais reduzido a partir da abertura política, mas a legislação ainda confere poderes de veto ao Exército (Decreto-Lei nํㅡㄹ 2.010/83).

15. Kraska e Cubelis (1997) observaram uma grande proliferação de unidades paramilitares nos Estados Unidos desde o final da Guerra Fria. Sua utilização ocorre cada vez mais em “batidas" pró-ativas, em "zonas quentes" de criminalidade. Anterior- 


\section{Mateus Afonso Medeiros}

mente, essas unidades eram empregadas apenas em situações de extrema gravidade. Na dimensão emprego, os autores afirmam uma grande militarização do policiamento estadunidense.

16. Em muitos momentos do período 1946-1964, governadores usaram ou ameaçaram usar as polícias militares como exércitos. Por exemplo, a ameaça de Juscelino Kubitschek de garantir sua candidatura à Presidência pelas armas (1955) e a defesa da posse de João Goulart, pelo governador Leonel Brizola (1961). No golpe de 1964, segundo a polícia mineira, 18 mil de seus homens marcharam para a Guanabara (Marco Filho, 1999:82-87).

17. A exposição de motivos da PEC 514/97 esclarece que "tal dispositivo, que fortalece a idéia de cooperação entre os entes federativos, reduz a possibilidade de uso excepcional das Forças Armadas em conflitos internos".

18. Ressalte-se que os currículos dos cursos de direito não possuem nenhuma disciplina relacionada à prática policial, além do Processo Penal.

19. A polícia civil não existe "para realizar a segurança pública", ou "para manter a ordem", mas para "registrar e investigar as ações e omissões definidas por lei como infrações penais, identificando as autorias e recolhendo provas que servirão de base aos membros do Ministério Público para o oferecimento da denúncia, peça inicial do procedimento criminal realizado pelo Poder Judiciário" (Minayo e Souza, 2003:67).

20. Nas palavras do coronel-PM Carlos Magno Cerqueira (1996:195), deve-se substituir a noção de "força pública que serve e protege" para a noção de "serviço público que pode usar a força".

21. Em fevereiro de 2002, treze deputados paulistas compareceram a Brasília para pedir a unificação das polícias ao então presidente da Câmara, Aécio Neves. Na comitiva, deputados do PT ao PPB, passando pelo PFL e pelo PSDB ("Câmara Acerta Cooperação com Assembléia Paulista", Agência Câmara, 21/2/2002).

22. $73 \%$ dos delegados entrevistados pelo IDESP concordam "totalmente" ou "em termos" com a unificação das polícias. Entretanto, teste estatístico revelou que os estados do Nordeste e do Centro-Oeste têm peso maior nas frações de discordância (Arantes e Cunha, 2003:129-130). Ressalte-se que a pesquisa foi realizada com base em uma pergunta genérica, sem especificar regras de transição ou alterações no inquérito policial.

23. Discute-se se essa subordinação é jurídica ou apenas operacional. Segundo as polícias, a Constituição Federal as vincula única e exclusivamente ao governador. Apesar da reunião formal das duas organizações na mesma Secretaria de Estado, ambas gozam de autonomia financeira e orçamentária.

24. Vide a recente criação do Instituto Brasileiro de Operadores de Segurança Pública IOSP, presidido pelo delegado mineiro Jésus Trindade Barreto Júnior.

25. O ponto fulcral da proposta é a implantação de "gabinetes integrados de segurança pública", operados em parceria por membros das organizações policiais, do Judiciário e dos Poderes Executivos federal e estadual. 


\section{REFERÊNCIAS BIBLIOGRÁFICAS}

ARANTES, Rogério B. e CUNHA, Luciana G. S. (2003), “Polícia Civil e Segurança Pública: Problemas de Funcionamento e Perspectivas de Reforma", in M. T. Sadek (org.), Delegados de Polícia. São Paulo, Sumaré, pp. 96-139.

BAYLEY, David H. (1975), "The Police and Political Development in England", in C. Tilly (ed.), The Formation of National States in Western Europe. Princeton, Princeton University Press, pp. 328-379.

. (1994), Police for the Future. New York, Oxford University Press.

BEATO FILHO, Cláudio Chaves. (s/d), "Ação e Estratégia das Organizações Policiais". Disponível em http://www.crisp.ufmg.br/acaoest.htm.

BICUDO, Hélio. (2000), “A Unificação das Polícias no Brasil”. Estudos Avançados, vol. $14, \mathrm{n}-40$, pp. $91-106$.

BITTNER, Egon. (2003), Aspectos do Trabalho Policial. São Paulo, EdusP.

BRASIL, Glaucíria Mota e ABREU, Domingos. (2002), “Uma Experiência de Integração das Polícias Civil e Militar: Os Distritos-Modelo em Fortaleza". Sociologias, ano 4, no 8, pp. 318-355.

CARVALHO, José Murilo de. (1981), A Construção da Ordem: A Elite Política Imperial. Brasília, Editora UnB.

. (2002), A Cidadania no Brasil: O Longo Caminho. Rio de Janeiro, Civilização Brasileira.

CASTRO, Jeanne Berrance de. (1977), A Milícia Cidadã: A Guarda Nacional de 1831 a 1850. São Paulo, Editora Nacional.

CERQUEIRA, Carlos Magno N. (1996), "Políticas de Segurança Pública para um Estado Democrático de Direito Chamado Brasil". Discursos Sediciosos - Crime, Direito e Sociedade, ano 1, no 2, pp. 191-211.

CINTRA, Antônio Octávio. (1974), “A Política Tradicional Brasileira: Uma Interpretação das Relações entre o Centro e a Periferia". Cadernos do Departamento de Ciência Política da UFMG, no 1, pp. 59-112.

COELHO, Edmundo Campos. (1976), Em Busca de Identidade: O Exército e a Política na Sociedade Brasileira. Rio de Janeiro, Forense Universitária.

_. (1989), “Constituição e Segurança Pública”. Indicador, vol. 7, nº 28, pp. 1.003-1.006.

COSTA, Arthur e MEDEIROS, Mateus. (2003), “A Desmilitarização das Polícias: Policiais, Soldados e Democracia". Teoria e Sociedade, vol. 1, no 11, pp. 66-89.

CRANK, John P. e LANGWORTHY, Robert. (1992), "An Institutional Perspective of Policing". The Journal of Criminal Law \& Criminology, vol. 83, n을, pp. 338-363.

DALLARI, Dalmo de Abreu. (1993), “Organização Policial Integrada”. Revista Trimestral de Direito Público, no 4, pp. 161-171.

FERNANDES, Heloísa Rodrigues. (1974), Política e Segurança. São Paulo, Alfa-Ômega. 


\section{Mateus Afonso Medeiros}

FERREIRA, Gabriela Nunes. (1999), Centralização e Descentralização no Império: O Debate entre Tavares Bastos e Visconde do Uruguai. São Paulo, Editora 34.

GRAHAM, Richard. (1997), Clientelismo e Política no Brasil do Século XIX. Rio de Janeiro, Editora UFRJ.

KANT DE LIMA, Roberto. (1995), A Polícia da Cidade do Rio de Janeiro: Seus Dilemas e Paradoxos. Rio de Janeiro, Forense.

. (2003), “Direitos Civis, Estado de Direito e ‘Cultura Policial': A Formação Policial em Questão". Revista Brasileira de Ciências Criminais, ano 11, no 41, pp. 241-256.

__, MISSE, Michel e MIRANDA, Ana Paula M. (2000), “Violência, Criminalidade, Segurança Pública e Justiça Criminal no Brasil: Uma Bibliografia". RBIB - Revista Brasileira de Informação Bibliográfica em Ciências Sociais, no - 50, pp. 45-123.

KRASKA, Peter B. e CUBELIS, Louis J. (1997), “Militarizing Mayberry and Beyond: Making Sense of American Paramilitary Policing". Justice Quarterly, vol. 14, nํㅜ 4, pp. 607-629.

LIN, Nan. (2001), Social Capital: A Theory of Social Structure and Action. New York, Cambridge University Press.

MARCH, James G. e OLSEN, Johan P. (1984), Rediscovering Institutions: The Organizational Basis of Politics. New York, The Free Press.

MARCO FILHO, Pe. Luiz de. (1999), História Militar da PMMG (6ª ed.). Belo Horizonte, Gradual Editora e Gráfica.

MCKENZIE, Ian e GALLAGHER, G. P. (1989), Behind the Uniform: Policing in Britain and America. New York, Harvester Wheatsheaf.

MEYER, John e ROWAN, Brian. (1991), “Institutionalized Organizations: Formal Structure as Myth and Ceremony", in W. W. Powell e P. J. DiMaggio (eds.), The New Institutionalism in Organizational Analysis. Chicago, University of Chicago Press, pp. 41-62.

MINAYO, Maria Cecília de Souza e SOUZA, Edinilsa Ramos de. (2003), Missão Investigar: Entre o Ideal e a Realidade de Ser Policial. Rio de Janeiro, Garamond.

MONJARDET, Dominique. (2003), O que Faz a Polícia. São Paulo, EdusP.

MORAES, Waldir Rodrigues de. (2001), "Bosquejo Histórico da Milícia Paulista". A Força Policial, no 30, pp. 51-98.

MUNIZ, Jacqueline. (2001), A Crise de Identidade das Polícias Militares Brasileiras: Dilemas e Paradoxos da Formação Profissional. Trabalho apresentado à REDES 2001. Washington, DC, Center for Hemispheric Defense Studies, 22-25 de maio.

OLIVEIRA, Luciano de. (1985), “Práticas Judiciárias em Comissariados de Polícia em Recife", in J. Lemgruber (org.), A Instituição Policial. Rio de Janeiro, Departamento de Publicações da Ordem dos Advogados do Brasil (OAB-RJ), pp. 187-206.

PAIXÃO, Antônio Luiz. (1982), “A Organização Policial numa Área Metropolitana”. Dados, vol. 25, nํㅜ 1, pp. 63-85. 
. (1985), "A Distribuição da Segurança Pública e a Organização Policial”, in J. Lemgruber (org.), A Instituição Policial. Rio de Janeiro, Departamento de Publicações da Ordem dos Advogados do Brasil (OAB-RJ), pp. 167-186.

POWELL, Walter W. (1991), "Expanding the Scope of Institutional Analysis", in W. W. Powell e P. J. DiMaggio (eds.), The New Institutionalism in Organizational Analysis. Chicago, University of Chicago Press, pp. 183-203.

e DIMAGGIO, P. J. (1991), “The Iron Cage Revisited: Institutional Isomorphism and Collective Rationality in Organizational Fields", in W. W. Powell e P. J. DiMaggio (eds.), The New Institutionalism in Organizational Analysis. Chicago, University of Chicago Press, pp. 63-82.

PRADO JUNIOR, Caio. (2000), Formação Política do Brasil: Colônia. São Paulo, Publifolha.

SADEK, Maria Tereza (org.). (2003), Delegados de Polícia. São Paulo, Sumaré.

SANTOS, José Nunes dos. (1985), "A Polícia Civil: Ligeiro Escorço Histórico", in J. Lemgruber (org.), A Instituição Policial. Rio de Janeiro, Departamento de Publicações da Ordem dos Advogados do Brasil (OAB-RJ), pp. 15-26.

SANTOS, José Vicente Tavares dos. (1997), “A Arma e a Flor: Formação da Organização Policial, Consenso e Violência”. Tempo Social, vol. 9, no 1, pp. 155-167.

SAPORI, Luís Flávio e SOUZA, Silas Barnabé de. (2001), “Violência Policial e Cultura Militar: Aspectos Teóricos e Empíricos". Teoria e Sociedade, nํㅡ, 7, pp. 173-214.

SCOTT, W. R. e MEYER, J. W. (1991), "The Organization of Societal Sectors", in W. W. Powell e P. J. DiMaggio (eds.), The New Institutionalism in Organizational Analysis. Chicago, University of Chicago Press, pp. 108-140.

SILVA, Jorge da. (2001), "Violência Policial e Ideologia dos Algozes-Vítima”, in D. Oliveira et alii, Violência Policial: Tolerância Zero? Goiânia, Editora UFG, pp. 69-84.

SILVA FILHO, José Vicente. (2001), “Fundamentos para a Reforma da Polícia”. Disponível em http://www.josevicente.com.br/pesquisas/pesqã05.htm.

SILVER, Allan. (1967), "The Demand for Order in Civil Society: A Review of Some Themes in the History of Urban Crime, Police, and Riot", in D. J. Bordua (ed.), The Police: Six Sociological Essays. New York, John Wiley \& Sons, Inc., pp. 1-24.

SOARES, Luiz Eduardo. (2000), “Uma Interpretação do Brasil para Contextualizar a Violência", in C. A. M. Pereira et alii, Linguagens da Violência. Rio de Janeiro, Rocco, pp. 23-46.

WEIR, Margaret. (1992), "Ideas and the Politics of Bounded Innovation", in S. Steinmo, K. Thelen e F. Longstreth (eds.), Structuring Politics: Historical Institutionalism in Comparative Analysis. New York, Cambridge University Press.

ZAVERUCHA, Jorge. (1992), “As Prerrogativas Militares nas Transições Brasileira, Argentina e Espanhola". Revista Brasileira de Ciências Sociais, ano 7, nํ19, pp. 56-65. 


\section{ABSTRACT}

\section{Institutional Aspects of Police Unification in Brazil}

This paper discusses the unification of the Brazilian military and civilian police forces, concentrating the empirical references from previous studies on the police forces in the States of São Paulo, Minas Gerais, and Rio de Janeiro. The approach does not focus on the efficiency of such a strategy in terms of crime control. Rather, the main preoccupation is with its legitimacy, as understood by the theory of organizations. Especially useful for this purpose is the concept of institutional field. The conclusion is that there is an incomplete institutionalization of the police field in Brazil. Throughout history, police forces have responded mostly to institutional demands from other fields, notably those of justice and defense. From this perspective, the unification proposal can be understood as an attempt to transform the nature of institutional demands directed towards police organizations.

Key words: police; unification; institutional field; organizations; police reform

\section{RÉSUMÉ}

Aspects Institutionnels de l'Unification des Polices au Brésil

Dans cet article, on examine l'unification des polices militaire et civile brésiliennes en cherchant les références empiriques dans des études précédentes réalisées au sujet des polices des États de São Paulo, Minas Gerais et Rio de Janeiro. Le point de vue de l'étude n'est pas axé sur le besoin d'unifier afin de contrôler la criminalité. Au lieu de l'efficacité, l'analyse se centre sur la légitimité de cette mesure, envisagée à la lumière de la théorie des organisations, et surtout du concept de champ institutionnel. On s'aperçoit que, au Brésil, on n'a pas une entière institutionnalisation du champ policier à proprement parler. Les polices ont dû répondre à des demandes institutionnelles venues d'autres domaines, surtout de ceux de la justice et de la défense. Sous cet angle, la proposition d'unification peut être perçue comme une tentative de transformation de la nature des demandes institutionnellles proposées aux organisations policières.

Mots-clé: police; unification; champ institutionnel; organisations; réforme policière 